\title{
A Systematic Review of the Effects of Environmental Pollutants, Chemical Factors, and Climate Changes on Children's Height
}

\author{
Maryam Vakil - Asadollahy ${ }^{1}$, Mojtaba Keikha ${ }^{2}$, Parinaz Poursafa ${ }^{3}$ and Roya Kelishadi ${ }^{1, *}$ \\ ${ }^{1}$ Pediatrics Department, Child Growth and Development Research Center, Research Institute for Primordial Prevention of Non Communicable Disease, Isfahan University of \\ Medical Sciences, Isfahan, Iran \\ ${ }^{2}$ Center for Health Related Social and Behavioral Sciences Research, Shahroud University of Medical Sciences, Shahroud, Iran \\ ${ }^{3}$ Environmental Health Engineering Department, Environment Research Center, Research Institute for Primordial Prevention of Non Communicable Disease, Isfahan \\ University of Medical Sciences, Isfahan, Iran \\ "Corresponding author: Roya Kelishadi, MD, Professor of Pediatrics, Pediatrics Department, Child Growth and Development Research Center, Research Institute for Primordial
} Prevention of Non Communicable Disease, Isfahan University of Medical Sciences, Isfahan, Iran. Fax: +98-3137923320, E-mail: kelishadi@med.mui.ac.ir

Received 2016 September 24; Revised 2017 December 30; Accepted 2018 February 05.

\begin{abstract}
Objective: Height is a multifactorial characteristic affected by genetics, hormonal and environmental factors. The aim of this study was to systematically review the effects of environmental pollutants, chemical factors, and climate changes on children and adolescents' height.

Methods: This study searched scientific databases including PubMed, ISI Web of Science, and Scopus using key words such as "Environmental Pollution”, “Climate Change”, “Growth”, "Body Height”, “Child and adolescent development”, and their combination. By removing duplicates, relevant papers were selected in three phases. This review included studies that were conducted among children and adolescents up to the age of 18 . After the quality assessment, data was extracted by a reviewer and rechecked by another one. The authors summarized information of 52 articles about the possible effects of environmental factors and climate change on height. Articles were divided to four categories, including air, soil, water pollutants, and climate changes.

Results: The evidence indicates that exposure to environmental pollutants have different effects on height growth; some of them, such as air pollution with lead, arsenic, fossil fuels and smoking, as well as exposure to nuclear radiation among children is associated with shorter stature, while exposure to some soil pollutants and airport noise did not have any effect on children's height growth.

Conclusions: The current study proposes that exposure to some environmental pollutants and chemicals during childhood and puberty might have negative effects on height growth. Therefore, various interventions are necessary for reducing the production of these pollutants and the exposure of growing children to these environmental factors.
\end{abstract}

Keywords: Environment, Height, Chemicals

\section{Introduction}

One of the indicators of health is height growth. Genetic, hormonal, and environmental factors might affect growth rate during various periods of life. Not long ago, genetic was supposed as the only determinant of height stature of children. Contrary to this hypothesis, studies, in which inheritance was assumed as the main reason of shortness, have mentioned positive changes in children's height by altering some environmental conditions, thus height is not merely affected by genetic factors (1-4). Hormonal factors are other influential factors of height growth. Growth Hormone (GH) is probably the most important hormone; any impairment in secretion can affect height growth negatively. Even by hormonal therapy in children with GH deficiency, optimal estimated height growth is not achieved. In addition to internal factors, nowadays, environmental pollutants, chemicals, and climate change are also highly considered to influence height (5-8). It has been suggested that even low levels of pollutants can negatively affect different health aspects, including children's height growth. Domestic sources or indoor pollutants as the producers of harmful pollutants, such as $\mathrm{NO}_{2}$ produced by ovens or smoking, have been noticed. In addition to domestic sources, various outdoor pollutants can affect children's health and growth as well, e.g. coal, radioactive emissions, and Endocrine Disruptor Compounds (EDCs). Moreover, climate change and rainfall have been shown to influence height status (6-9).

Insecticides and pesticides are among those pollu- 
tants, which have been used widely both indoors and outdoors. These pollutants effect children's growth, and some of them, such as dichlorodiphenyltrichloroethane, are prohibited since long ago yet because of their effectiveness, are still being used $(1,2)$.

Chemical factors, such as Arsenic, can enter the body through water and inspiration has been shown to affect children's growth $(3,4)$.

Because of the importance of growth in children and adolescents, identifying modifiable factors that might affect children's height would be useful. Based on what was mentioned above and controversial reports of previous studies, this study was conducted to provide a general systematic review of environmental pollutants, chemical factors, and climate changes on children and adolescent's height.

\section{Methods}

To find relevant literature regarding the relationship between environmental factors and climate changes and height, the researchers searched scientific databases, including PubMed, ISI Web of Science, and Scopus with no restriction of time, during year 2014.

Scopus was searched via Emtree Thesaurus terms and pubmed via Medical Subject heading (MeSH) and also key words including "Air Pollution" (5) OR "Air Polutants" (5) OR "Water Pollution" (5) OR "Water Polutants" (5) OR "Environmental Pollution" (5) OR "Soil Pollutants" (5) OR “Climate Change" (5) AND ("Growth" (5) OR "Child Development" (5) OR "Growth and Development" (5) OR "Adolescent Development" (5) OR "Body Height" OR "Body weight and Measures" (5)) AND ("Child" (5) OR "Child, Preschool" (5) OR "Adolescent" (5)).

EndNote software was utilized in order to eliminate duplicated studies. Two reviewers separately read the title and abstract of selected studies. In this step, only relevant articles were selected for the review and non - relevant articles were declined. After that, full text of papers was retrieved and read carefully for extraction of the needed data. If there was any disagreement between the two reviewers, it was solved with consultation and consensus.

In the next step, the eligibility of relevant papers was checked. The authors included papers conducted on children and adolescents up to age 18 , and provided data on the effects of environmental pollutants and/or climate changes on the height of children and/or adolescents. The studies were conducted between years 1975 and 2013.

The researchers excluded papers, which reported parameters of growth other than height, or reported body mass index (BMI) without providing the results of height separately.
Identification of main findings of studies was conducted on a case - by - case basis and included statistical analyses that might have been conducted, with consistency of the general pattern across exposure groups.

The following items were extracted from relevant papers:

a. general information of the study (first author's name, publication year, location of the study, years of the study, and study design); b. the information of the study population (gender and age of participants and sample size); c. the aim of the study; and d. the study findings about the effect of environment on height. One reviewer extracted the data and the other checked the extracted data.

\section{Results}

In the initial search, 1746 articles were found that matched the searched terms. After studying their abstracts, appropriate studies consistent with inclusion criteria of the current review were selected and 52 articles were included (Figure 1).

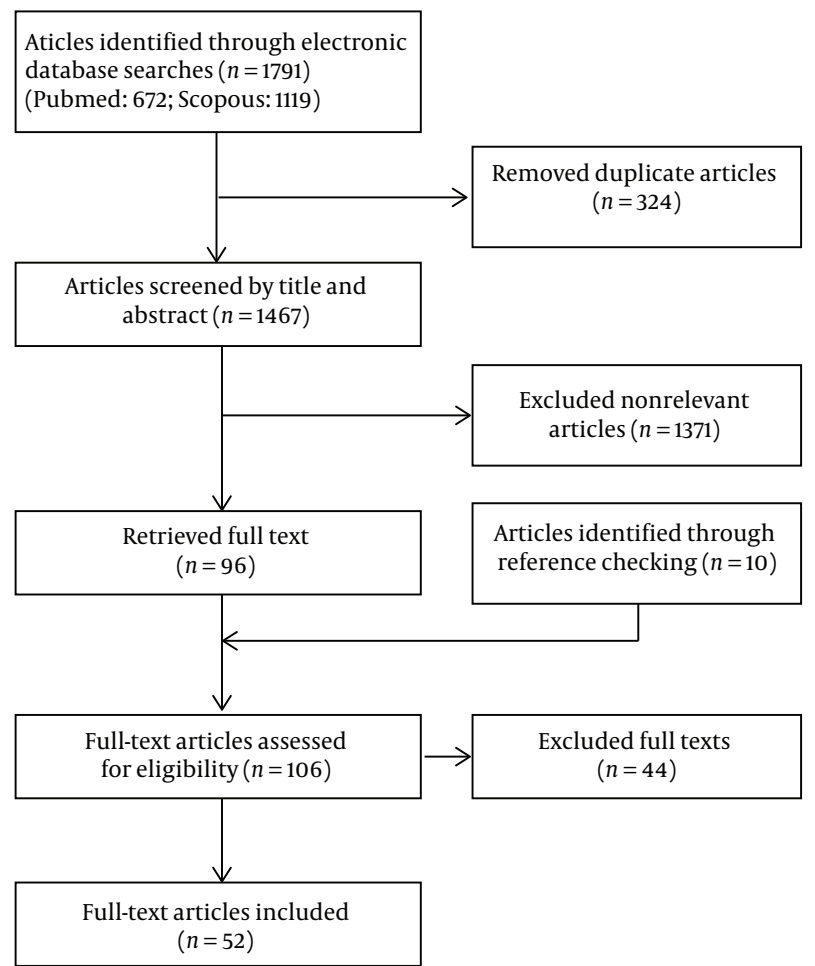

Figure 1. Study Flowchart

Articles allocated to four categories, including soil pollutants (10 articles), air pollutants (33 articles), water pollu- 
tants ( 6 articles), and climate change (3 articles).

\subsection{Soil Pollutants}

Among included articles, 10 studies were about soil. The pollutants were:

1. Polybrominated Biphenyl (PBB)

2. Polychlorobiphenyls (PCB)

\section{DIOXINs}

4. P,P'- dichlorodiphenyldichloroethylene (P,P'-DDE)

5. P,P'- dichlorodiphenyltrichloroethane (P,P'-DDT)

6. Polychlorinated Organic Compounds (POCs)

7. Dichlorodiphenyldichloroethylene (DDE)

8. Cadmium

\section{1 - hydroxypyrene (1 - OHP)}

Seven of these articles assessed the effect of PCBs as soil pollutants on height growth; five of them did not report any significant association between PCBs and height growth of children (6-10), whereas two studies found significant associations between PCBs and their different combinations on height stature and low BMI in first year of life $(11,12)$.

The next soil pollutant was DDE that was assessed in four studies. In an evaluation about concentration of P, P'DDE amongst breastfed children of exposed mothers, in infants aged up to six months, height growth was not influenced (7), whereas in two other studies, prenatal DDE exposure was in accordance with shortness of all ages, especially in four- to seven - year-old age group $(1,2)$. A study that assessed DDE exposure effects according to gender, showed that this exposure was in association with female's height for about $1.8 \mathrm{~cm}$ shorter stature, yet it seemed not to have any effects on male's height (9).

Some studies reported that exposure to P, P' - DDT, DDE, and $\mathrm{PBB}$ did not affect height growth rate $(6,13)$. In another study, the significant effect of dioxin on height growth was shown (11). According to the results of another study, Cadmium exposure affected both males and females negatively and caused failure to thrive (FTT), yet 1 - OHP only affected males (10).

\subsection{Water Pollutants}

A total of six articles were about the effects of water pollutants on height growth. A study showed that treated water affected height stature positively, especially in one- to four-year-old children; these reports were compared with consumption of both treated and untreated water, concurrently (14).

Methyl - mercury high concentration in umbilical cord blood had a negative correlation with height growth in 18 - month - old children (15). In another study, the family fish consumption was not in accordance with mental development and linear growth of less than five-year-old children (3).

It is presented that Arsenic exposure in early childhood might have considerable negative effects on height and weight, whereas prenatal exposure had lower effects, with prominence in females (4). In another study, the average height of children exposed to Arsenic, Fluoride or both was lower than their counterparts (16).

Intrauterine exposure to persistent organochlorine pollutants (POPs), defined as fish consumption of pregnant mothers, is presented to be in association with lower average height in comparison with controls (17).

\subsection{Air Pollutants}

Among air pollutants, most studies have been conducted on the effects of exposure to lead and cigarettes smoke. One study reported no significant association between prenatal lead exposure and height growth at the age of four (18); likewise, another study did not present any association between mid-pregnancy exposure to lead and height growth in the entire pediatric age group (19). Another study revealed opposite results and reported that both prenatal and postnatal lead exposure might cause short stature of two- to three - year - old children (20); likewise another study reported the same results in children less than two years old (18). Six studies found that exposure to lead could have a negative influence on children and adolescents' height (21-26). A study reported an association between higher blood lead levels and shorter average height, yet this result was not statistically significant in comparison to controls (27). Overall, eight to ten articles had referred to the impact of lead on short stature and two other papers did not confirm this relationship.

Among studies about the effects of passive smoking on children's height growth, six papers presented significant negative effects on children's height. In these studies, cigarette smoking of pregnant mothers, smoking of mother or both parents after childbirth, and exposure of children to tobacco smoke were all associated with children's short stature (28-33). In another study, children of 
smoker mothers had shorter height, yet this was not statistically significant (34). Some studies had contradictory findings and did not find any association between parental smoking and height growth in children (35-37). Overall, among ten articles about smoking, six studies confirmed the association of smoking with short stature of children, and four studies did not.

Four studies had assessed the effects of fossil fuels and the use of gas for cooking at home and their impact on children's height. All these papers suggested the possible relationship of children short stature and fossil fuels and gas use (32, 38-40). Significant association between males' height and intrauterine exposure to fossil fuels was reported while no association was found in females (41). However, another study did not find any association between fossil fuels consumption and children height growth regardless of gender (42).

In two different studies, living near landfills, as an environmental factor, was significantly associated with short stature in children, presented separately by Paigen B et al. and Ocampo CE et al. $(43,44)$.

Two studies reported a significant association between environmental air pollution and height growth in the pediatric age group. Cleaner air status posed better height growth $(45,46)$.

The negative effects of exposure to cadmium and arsenic on children's height growth were documented in two studies; these effects were greater in females. Moreover, growth period exposure had affected growth rate in a more negative manner in comparison to prenatal exposure $(47,48)$.

Living in the vicinity of airport causing noise exposure did not affect height growth (49). It was reported that living in Hiroshima caused shorter stature, as these children were exposed to high doses of nuclear radiations (50).

\subsection{Climate Changes}

A group of researchers found that rainfall changes influenced two-to five-year-old female's height in a negative manner, yet there was no significant association in other age groups (11). In a study in Amazon, different ranges of rainfall during early childhood had a negative association with adult female height. Among females, each 10\% increase in the coefficient of variation of rainfall during the age of two to five years old was associated with $0.7 \%$ to $1.2 \%$ shorter adult height. This study suggested that environmental distresses after cessation of weaning might have the strongest effects on adult height (51).

A study in Tibet conducted by Argnani et al. showed that living in higher altitudes might be associated with short stature of children (52).

\section{Discussion}

This review proposes that some environmental pollutants and chemicals have adverse effects on height growth. Products that disrupt the endocrine system are those persistent organic compounds in the nature including; $\mathrm{PCB}$, PBB and P, P'- DDT. Maternal exposure to these products in nature, especially through the soil, can lead to transfer of these pollutants to children. In the study of Pan et al. during year 2010 in USA, the breast milk levels of these pollutants and also children's blood levels were measured, thereafter height growth charts were evaluated, and results did not show a significant association (50). Five other similar studies reported the same results $(6,8,9,13,25)$. However, Burns et al. (2011) reported a significant association between children short stature and exposure to $\mathrm{PCB}$, PBB, P,P'- DDT, and Dioxin (11). Burns et al. in the study conducted during 2012 on 499 males represented this significant effect, especially in eight- and nine - year - olds (2).

Dhooge et al. measured the urinary level of cadmium in 14- to 15 - year - old males and females and found that higher levels of cadmium negatively affected children's growth (10).

In the study of Esrey et al. in 1988, the height difference of children, who used treated water in comparison with children, who used refined and untreated water was concurrently significant. Refined water usage was associated with greater height growth among one- to four - year - old children yet not infants. This association was to the extent that 4.4 centimeter more height growth was expected in the first five years of life (14).

In two studies about the effect of methyl mercury found in sea food on children's linear height growth, one mentioned negative effect in 18 months while the other presented no effect in children under five years old $(3,15)$.

Saha et al. found the dramatic effect of postnatal arsenic exposure yet not prenatal (19), which was similar to another study (16).

In the study of Rylander et al. in 2007 in Sweden, intrauterine exposure to POPs due to mother's fish consumption was evaluated and the results showed that the average height of POPs - exposed children was lower in comparison with the control group in a way that children of mothers, who had consumed more fish during pregnancy, had shorter height amongst four- to seven - year - olds (17).

In 2008, Lamb et al. reported that prenatal lead exposure was not significantly associated with height growth (19). Based on the results, postnatal lead exposure in the first 48 months affected height growth more in comparison to prenatal exposure. Also, linear height growth in postnatal first 48 months of lead exposure was not statistically significant in comparison to the prenatal period (18). 
In the study of Mahram et al., lead exposure did not have a negative effect on height growth (27). While in the study of Sanna et al. conducted in Italy, significant effect of lead exposure on height growth in 11- to 14 - year - old children in comparison with the control group was mentioned (25). Other seven reports indicated that living in areas with lead polluted air could lead to children's short stature as compared with the control group $(18,20-24,26)$.

In Japan, in 2012, Ino et al. assessed the effect of maternal smoking on height growth of 1366, nine- to ten - year old children and found shorter stature of children whose mothers were exposed to cigarette smoke as compared with those whose mothers weren't exposed (35). Similar results were presented by five other studies $(28-30,32,33)$. In 2013 , in the similar study of Yang et al. on 6.5 -year - old children, parental smoking and children growth did not have a significant association (35). This was also reported by three other studies $(34,36,37)$.

In the study of Kyu et al., use of fossil fuels caused a reduction in children's height growth (32). In four other studies conducted in different regions from 2007 to 2011, significant impact of fossil fuels and related pollutants on short stature of children were represented (38-41). However, in a study on South African children, no association between biomass usage and height growth in six- to 36 month - old children after adjustment of age, gender, and birth weight was found (42).

Ocampo in Colombia found that near landfills birth was in accordance with lower Z-Score, while this effect was not found among people, who had migrated to these areas (44). Paigen et al. stated that people that lived in these areas for at least a duration of $75 \%$ of their lives had shorter height (43).

Bobak et al. mentioned after - birth air pollution exposure as an underlying factor for short stature of children (45). They also presented air pollution inverse association with height in all ages except 15 -year-olds. Two years living in air polluted areas caused a 0.6 - $\mathrm{cm}$ shorter height of children. This height difference increased to $1.2 \mathrm{~cm}$ by seven years of living in polluted areas yet the difference was gradually reduced and at last no significant association was reported in 15 - year - old adolescents (46).

In a cohort study about maternal and fetal exposure to lead and cadmium on height growth of Bangladeshi children up to five years old, the higher urinary concentration of lead and cadmium in both mothers and fetuses was in association with shorter height of fetuses (47), this was similar to the results of the study of Lin et al. on three-yearold children (48).

In 1985, Lawrence et al. investigated the effects of airport noise on children's height growth yet they did not find any association compared with the control group (49).
Another study presented that children exposed to high doses of nuclear radiation in Hiroshima and Nagasaki had shorter height. Being exposed to radiation at younger ages affected height growth more steeply (50).

Godoy et al. in two different studies about the association of rainfall, rainfall changes, and temperature with height growth, reported that the level and CV of rain during the first four years of age were associated with taller stature $(51,53)$.

Argnani et al. in 2008 compared Tibetan children linear growth and altitude of living location. They presented an average reduction in linear growth of children living at 4000 meters in comparison with those at 3500 meters yet it seemed this difference was due to weaker nutritional and socio - economic conditions of these people (52).

\subsection{Conclusion}

According to the available evidence and review of the articles that have been retrieved in this systematic review, the presence and exposure to some of the chemical and environmental pollutants is related to the growth, and especially the height of children and adolescents. Although other possible confounders may be feasible in such investigations, and in order to determine and make a more definitive statement, the use of some tools (meta - analysis methods) to quantitatively demonstrate the impact of the relationship between the presence of environmental pollutants and the height of children and adolescents seems useful, yet according to the evidence, it seems that the effect of these pollutants on the height of children and adolescents is undeniable. Below is a summary of some available evidence:

Among soil pollutants, dioxin, cadmium, and 1 - OHP and among water pollutants, exposure to POPs, arsenic, fluoride, and untreated water affected height growth of children. Also, air pollution and levels of lead, cadmium and arsenic in the air, exposure to tobacco smoke, the use of fossil fuel at home for cooking and exposure to nuclear radiation among children was associated with shorter stature.

On the other hand, exposure to PCBs, PBB and P,P'DDT, and airport noise, as environmental pollutant, did not have any impact on children's height growth.

Regarding DDE and P,P'- DDE in soil and also methyl - mercury exposure by seafood consumption, amount of rainfall, changes in rainfall and sea surface height and their impact on height growth, due to contradictory results, further studies are suggested.

Considering the adverse effects of these pollutants on human health, programs for public health intervention to reduce environmental pollutants, and short height protection is necessary. 


\section{Supplementary Material}

Supplementary material(s) is available here [To read supplementary materials, please refer to the journal website and open PDF/HTML].

\section{Footnote}

Funding/Support: The study was conducted as a thesis funded by Isfahan University of Medical Sciences, Isfahan, Iran

\section{References}

1. Ribas-Fito N, Gladen BC, Brock JW, Klebanoff MA, Longnecker MP. Prenatal exposure to 1,1-dichloro-2,2-bis (p-chlorophenyl)ethylene (p,p'DDE) in relation to child growth. Int JEpidemiol. 2006;35(4):853-8. doi: 10.1093/ije/dyl067. [PubMed: 16606643].

2. Burns JS, Williams PL, Sergeyev O, Korrick SA, Lee MM, Revich $B$, et al. Serum concentrations of organochlorine pesticides and growth among Russian boys. Environ Health Perspect. 2012;120(2):3038. doi: 10.1289/ehp.1103743. [PubMed: 21984531]. [PubMed Central: PMC3279441].

3. Marques RC, Bernardi JV, Dorea JG, Brandao KG, Bueno L, Leao RS, et al. Fish consumption during pregnancy, mercury transfer, and birth weight along the Madeira River Basin in Amazonia. Int J Environ Res Public Health. 2013;10(6):2150-63. doi: 10.3390/ijerph10062150. [PubMed: 23759951]. [PubMed Central: PMC3717729].

4. Saha KK, Engstrom A, Hamadani JD, Tofail F, Rasmussen KM, Vahter M. Pre- and postnatal arsenic exposure and body size to 2 years of age: a cohort study in rural Bangladesh. Environ Health Perspect. 2012;120(8):1208-14. doi: 10.1289/ehp.1003378. [PubMed: 22504586]. [PubMed Central: PMC3440068].

5. Goyal O, Sidhu SS, Kishore H. Minimal hepatic encephalopathy in cirrhosis- how long to treat? Ann Hepatol. 2017;16(1):115-22. doi: 10.5604/16652681.1226822. [PubMed: 28051800].

6. Blanck HM, Marcus M, Rubin C, Tolbert PE, Hertzberg VS, Henderson AK, et al. Growth in girls exposed in utero and postnatally to polybrominated biphenyls and polychlorinated biphenyls. Epidemiology. 2002;13(2):205-10. [PubMed: 11880762].

7. Pan IJ, Daniels JL, Herring AH, Rogan WJ, Siega-Riz AM, Goldman BD, et al. Lactational exposure to polychlorinated biphenyls, dichlorodiphenyltrichloroethane, and dichlorodiphenyldichloroethylene and infant growth: an analysis of the Pregnancy, Infection, and Nutrition Babies Study. Paediatr Perinat Epidemiol. 2010;24(3):262-71. doi: 10.1111/j.1365-3016.2010.01114.x. [PubMed: 20415756]. [PubMed Central: PMC2872251].

8. Mazhitova Z, Jensen S, Ritzen M, Zetterstrom R. Chlorinated contaminants, growth and thyroid function in schoolchildren from the Aral Sea region in Kazakhstan. Acta Paediatr. 1998;87(9):991-5. [PubMed: 9764896].

9. Karmaus W, Asakevich S, Indurkhya A, Witten J, Kruse H. Childhood growth and exposure to dichlorodiphenyl dichloroethene and polychlorinated biphenyls. J Pediatr. 2002;140(1):33-9. doi: 10.1067/mpd.2002.120764. [PubMed: 11815761].

10. Dhooge W, Den Hond E, Koppen G, Bruckers L, Nelen V, Van De Mieroop E, et al. Internal exposure to pollutants and body size in Flemish adolescents and adults: associations and dose-response relationships. Environ Int. 2010;36(4):330-7. doi: 10.1016/j.envint.2010.01.005. [PubMed: 20181395].
11. Burns JS, Williams PL, Sergeyev O, Korrick S, Lee MM, Revich B, et al. Serum dioxins and polychlorinated biphenyls are associated with growth among Russian boys. Pediatrics. 2011;127(1):e59-68 doi: 10.1542/peds.2009-3556. [PubMed: 21187307]. [PubMed Central: PMC3010086].

12. Guo YL, Lin CJ, Yao WJ, Ryan JJ, Hsu CC. Musculoskeletal changes in children prenatally exposed to polychlorinated biphenyls and related compounds (Yu-Cheng children). J Toxicol Environ Health. 1994;41(1):83-93. doi: 10.1080/15287399409531828. [PubMed: 8277528].

13. Cupul-Uicab LA, Hernandez-Avila M, Terrazas-Medina EA, Pennell ML, Longnecker MP. Prenatal exposure to the major DDT metabolite 1,1-dichloro-2,2-bis(p-chlorophenyl)ethylene (DDE) and growth in boys from Mexico. Environ Res. 2010;110(6):595-603. doi: 10.1016/j.envres.2010.06.001. [PubMed: 20566194]. [PubMed Central: PMC2935620].

14. Esrey SA, Habicht JP, Latham MC, Sisler DG, Casella G. Drinking water source, diarrheal morbidity, and child growth in villages with both traditional and improved water supplies in rural Lesotho, southern Africa. Am J Public Health. 1988;78(11):1451-5. [PubMed: 3177718] [PubMed Central: PMC1350237].

15. Grandjean P, Budtz-Jorgensen E, Steuerwald U, Heinzow B, Needham LL, Jorgensen PJ, et al. Attenuated growth of breast-fed children exposed to increased concentrations of methylmercury and polychlorinated biphenyls. FASEB J. 2003;17(6):699-701. doi: 10.1096/fj.020661fje. [PubMed: 12586743].

16. Wang SX, Wang ZH, Cheng XT, Li J, Sang ZP, Zhang XD, et al. Arsenic and fluoride exposure in drinking water: children's IQ and growth in Shanyin county, Shanxi province, China. Environ Health Perspect. 2007;115(4):643-7. doi: 10.1289/ehp.9270. [PubMed: 17450237]. [PubMed Central: PMC1852689].

17. Rylander L, Stromberg U, Hagmar L. Weight and height at 4 and 7 years of age in children born to mothers with a high intake of fish contaminated with persistent organochlorine pollutants. Chemosphere. 2007;67(3):498-504. doi: 10.1016/j.chemosphere.2006.09.089. [PubMed: 17123573].

18. Afeiche M, Peterson KE, Sanchez BN, Schnaas L, Cantonwine D, Ettinger AS, et al. Windows of lead exposure sensitivity, attained height, and body mass index at 48 months. J Pediatr. 2012;160(6):1044-9. doi: 10.1016/j.jpeds.2011.12.022. [PubMed: 22284921]. [PubMed Central: PMC3360798].

19. Lamb MR, Janevic T, Liu X, Cooper T, Kline J, Factor-Litvak P. Environmental lead exposure, maternal thyroid function, and childhood growth. Environ Res. 2008;106(2):195-202. doi: 10.1016/j.envres.2007.09.012. [PubMed: 17988663].

20. Shukla R, Dietrich KN, Bornschein RL, Berger O, Hammond PB. Lead exposure and growth in the early preschool child: a follow-up report from the Cincinnati Lead Study. Pediatrics. 1991;88(5):886-92. [PubMed: 1945627].

21. Factor-Litvak P, Wasserman G, Kline JK, Graziano J. The Yugoslavia Prospective Study of environmental lead exposure. Environ Health Perspect. 1999;107(1):9-15. [PubMed: 9872712]. [PubMed Central: PMC1566313].

22. Ballew C, Khan LK, Kaufmann R, Mokdad A, Miller DT, Gunter EW. Blood lead concentration and children's anthropometric dimensions in the Third National Health and Nutrition Examination Survey (NHANES III), 1988-1994. J Pediatr. 1999;134(5):623-30. [PubMed: 10228299].

23. Little BB, Spalding S, Walsh B, Keyes DC, Wainer J, Pickens S, et al Blood lead levels and growth status among African-American and Hispanic children in Dallas, Texas-1980 and 2002: Dallas Lead Project II. Ann Hum Biol. 2009;36(3):331-41. doi: 10.1080/03014460902806615. [PubMed: 19381987].

24. Rahman A, Maqbool E, Zuberi HS. Lead-associated deficits in stature mental ability and behaviour in children in Karachi. Ann Trop Paediatr. 2002;22(4):301-11. doi: 10.1179/027249302125001958. [PubMed: 12530279]. 
25. Sanna E, Vallascas E. Hair lead levels to evaluate the subclinical impact of lead on growth in Sardinian children (Italy). Am J Hum Biol. 2011;23(6):740-6. doi:10.1002/ajhb.21203. [PubMed: 21858896].

26. Lauwers MC, Hauspie RC, Susanne C, Verheyden J. Comparison of biometric data of children with high and low levels of lead in the blood Am J Phys Anthropol. 1986;69(1):107-16. doi: 10.1002/ajpa.1330690112. [PubMed: 3946592].

27. Mahram M, Mousavinasab N, Dinmohammadi H, Soroush S, Sarkhosh F. Effect of living in lead mining area on growth. Indian J Pediatr. 2007;74(6):555-9. [PubMed: 17595498].

28. Rona RJ, Florey CD, Clarke GC, Chinn S. Parental smoking at home and height of children. BrMed J(Clin Res Ed).1981;283(6303):1363. [PubMed: 6797543]. [PubMed Central: PMC1507791].

29. Rona RJ, Chinn S, Florey CD. Exposure to cigarette smoking and children's growth. Int J Epidemiol. 1985;14(3):402-9. [PubMed: 4055207].

30. Berkey CS, Ware JH, Speizer FE, Ferris BG Jr. Passive smoking and height growth of preadolescent children. Int J Epidemiol. 1984;13(4):454-8. [PubMed: 6519884].

31. Ino T, Shibuya T, Saito K, Inaba Y. Relationship between body mass index of offspring and maternal smoking during pregnancy. Int J Obes (Lond). 2012;36(4):554-8. doi: 10.1038/ijo.2011.255. [PubMed: 22184058].

32. Kyu HH, Georgiades K, Boyle MH. Maternal smoking, biofuel smoke exposure and child height-for-age in seven developing countries. Int J Epidemiol. 2009;38(5):1342-50. doi: 10.1093/ije/dyp253. [PubMed 19622677].

33. Berlanga Mdel R, Salazar G, Garcia C, Hernandez J. Maternal smoking effects on infant growth. Food Nutr Bull. 2002;23(3 Suppl):142-5 [PubMed: 12362783]

34. Ino $\mathrm{T}$, Shibuya $\mathrm{T}$, Saito $\mathrm{K}$, Ohtani $\mathrm{T}$. Effects of maternal smoking during pregnancy on body composition in offspring. Pediatr Int. 2011;53(6):851-7. doi: 10.1111/j.1442-200X.2011.03383.x. [PubMed 21496178]

35. Yang S, Decker A, Kramer MS. Exposure to parental smoking and child growth and development: a cohort study. BMC Pediatr. 2013;13:104 doi: 10.1186/1471-2431-13-104. [PubMed: 23842036]. [PubMed Central: PMC3717101]

36. Fried PA, James DS, Watkinson B. Growth and pubertal milestones during adolescence in offspring prenatally exposed to cigarettes and marihuana. Neurotoxicol Teratol. 2001;23(5):431-6. [PubMed: 11711245].

37. Fried PA, Watkinson B, Gray R. Growth from birth to early adolescence in offspring prenatally exposed to cigarettes and marijuana. Neurotoxicol Teratol.1999;21(5):513-25. [PubMed: 10492386].

38. Burton A. Coal fire emissions curb children's growth. Environ Health Perspect. 2011;119(6):A246-7. doi: 10.1289/ehp.119-a246a. [PubMed 21628123]. [PubMed Central: PMC3114835].

39. Jedrychowski W, Khogali M, Elkarim MA. Height and lung function in preadolescent children of Kuwaitis and European origin: a pilot survey on health effects of gas cooking in the Middle East. Arch Environ Health. 1991;46(6):361-5. doi: 10.1080/00039896.1991.9934403. [PubMed: 1772261].
40. Mishra V, Retherford RD. Does biofuel smoke contribute to anaemia and stunting in early childhood? Int JEpidemiol.2007;36(1):117-29. doi: 10.1093/ije/dyl234. [PubMed:17085456].

41. Ranjan N, Sarangi S, Padmanabhan VT, Holleran S, Ramakrishnan R, Varma DR. Methyl isocyanate exposure and growth patterns of adolescents in Bhopal. JAMA. 2003;290(14):1856-7. doi: 10.1001/jama.290.14.1856. [PubMed: 14532313].

42. Machisa M, Wichmann J, Nyasulu PS. Biomass fuel use for household cooking in Swaziland: is there an association with anaemia and stunting in children aged 6-36 months? Trans R Soc Trop Med Hyg. 2013;107(9):535-44. doi: 10.1093/trstmh/trt055. [PubMed: 23900119].

43. Paigen B, Goldman LR, Magnant MM, Highland JH, Steegmann AJ. Growth of children living near the hazardous waste site, Love Canal. Hum Biol.1987;59(3):489-508. [PubMed: 3610123].

44. Ocampo CE, Pradilla A, Mendez F. [Impact of a waste disposal site on children physical growth]. Colombia Medica. 2008;39(3):253-9. Spanish.

45. Jedrychowski W, Maugeri U, Jedrychowska-Bianchi I. Body growth rate in preadolescent children and outdoor air quality. Environ Res. 2002;90(1):12-20. [PubMed: 12359186].

46. Bobak M, Richards M, Wadsworth M. Relation between children's height and outdoor air pollution from coal-burning sources in the British 1946 birth cohort. Int Arch Occup Environ Health. 2004;77(6):383-6. doi: 10.1007/s00420-004-0522-5. [PubMed: 15338223].

47. Gardner RM, Kippler M, Tofail F, Bottai M, Hamadani J, Grander M, et al. Environmental exposure to metals and children's growth to age 5 years: a prospective cohort study. Am J Epidemiol. 2013;177(12):135667. doi: 10.1093/aje/kws437. [PubMed: 23676282]. [PubMed Central: PMC3676155]

48. Lin CM, Doyle P, Wang D, Hwang YH, Chen PC. Does prenatal cadmium exposure affect fetal and child growth? Occup Environ Med. 2011;68(9):641-6. doi: 10.1136/oem.2010.059758. [PubMed: 21186202].

49. Schell LM, Hodges DC. Longitudinal study of growth status and airport noise exposure. Am J Phys Anthropol. 1985;66(4):383-9. doi: 10.1002/ajpa.1330660406. [PubMed: 3993764].

50. Belsky JL, Blot WJ. Adult stature in relation to childhood exposure to the atomic bombs of Hiroshima and Nagasaki. Am J Public Health. 1975;65(5):489-94. [PubMed: 1130572]. [PubMed Central: PMC1775858].

51. Godoy R, Tanner S, Reyes-Garcia V, Leonard WR, McDade TW, Vento M, et al. The effect of rainfall during gestation and early childhood on adult height in a foraging and horticultural society of the Bolivian Amazon. Am J Hum Biol. 2008;20(1):23-34. doi: 10.1002/ajhb.20679. [PubMed: 17941036].

52. Argnani L, Cogo A, Gualdi-Russo E. Growth and nutritional status of Tibetan children at high altitude. Coll Antropol. 2008;32(3):807-12. [PubMed: 18982755].

53. Godoy R, Goodman E, Reyes-Garcia V, Eisenberg DT, Leonard WR, Huanca T, et al. Rain, temperature, and child-adolescent height among Native Amazonians in Bolivia. Ann Hum Biol. 2008;35(3):27693. doi: 10.1080/03014460801968540. [PubMed: 18568593]. 